\section{Epinephrine auto-injection radically increases risk for clostridial infection and necrotizing fasciitis}

\author{
Kenneth Larson, ${ }^{1}$ Gary Grone, ${ }^{2}$ \\ Cindy L. Austin, ${ }^{3}$ Simon J. Thompson ${ }^{3}$ \\ 1 Trauma \& Burn Surgery Center; \\ ${ }^{2}$ Department of Trauma Services; ${ }^{3}$ Trauma \\ \& Burn Research, Mercy Hospital, \\ Springfield, MO, USA
}

\begin{abstract}
Clostridial perfringens is a bacteria commonly found on skin flora. Due to the optimal growth environment intramuscular epinephrine injections predispose patients to the rapid development of clostridial myonecrosis. There have been only four cases, including this one, reported in the last 60 years of pediatric Clostridium perfringens infections post-epinephrine injection. We detail the successful management of a 16 year old, immunocompetent female who developed gas gangrene and necrotizing fasciitis on her thigh secondary to clostridial infection after utilization of an Epinephrine Auto-Injector and review the pediatric literature of patients with Clostridial perfringens secondary to epinephrine injection. We define common clinical signs and symptoms of clostridial infection from the review of the literature. The relevance of our findings is to raise awareness among emergency physicians when patients present following an injection in order to reduce diagnostic delay that could result in amputation or death.
\end{abstract}

\section{Introduction}

Necrotizing fasciitis (NF) is within the general category of necrotizing soft tissue infection (NSTI). There are three variants of NSTI: i) NF, ii) necrotizing cellulitis, and iii) myonecrosis. However, NF is often used in clinical settings as a broadly inclusive term for overlapping types of NSTI; ${ }^{1}$ thus for the purposes of this paper, the authors will use the broadly inclusive term NF. Clostridial myonecrosis is an infection primarily of muscle tissue, of which 90 percent are Clostridium perfringens. ${ }^{2}$ Clostridial myonecrosis or gas gangrene is a highly lethal necrotizing soft tissue infection of skeletal muscle caused by toxin- and gasproducing Clostridium species. ${ }^{3}$

Currently, $90 \%$ of contaminated wounds demonstrate clostridial organisms, but less than 2\% develop clostridial myonecrosis. ${ }^{3}$ This emphasizes the significance of both host and local wound elements in the development of this process, rather than the mere incidence of the organisms in the wound. For this reason, there have been only four cases, ${ }^{4-6}$ including this one, reported in the last 60 years of pediatric Clostridium perfringens infections secondary to epinephrine injection. This review of the literature describes these cases, as well as, a recent case detailing the manifestation of gas gangrene and necrotizing fasciitis caused by Clostridium perfringens.

To the best of our knowledge, this is the first reported pediatric case in the last 35 years. We describe risk factors related to the epinephrine injection that contributed to the development of Clostridia infection, as well as antibiotic therapy, pain medications, surgical debridement, and wound vacuum assisted closure (VAC) therapy management.

\section{Case Report}

After a consult at a Pediatric Urgent Care (Day 0), the 16-year-old female was transferred to the Emergency Department (ED) with suspected Compartment Syndrome. Approximately 24 hours prior, she reported administering an [Epinephrine AutoInjector (EAI)]; Brand: EpiPen, dose: $0.3 \mathrm{mg})]$ due to an allergic reaction with the symptoms of hives and difficulty breathing. Upon presentation to the ED, no clinical signs of anaphylaxis were evident.

Upon arrival (Day 0), patient presented with tenderness and mild swelling of the left thigh and the initial vital signs were: [Heart Rate (HR)] 120bpm; [Blood Pressure (BP)] 100/55mmHg; Respiratory rate $18 \mathrm{bpm}$; Temperature $98.8^{\circ} \mathrm{F}$. The emergency physician prescribed fluids, oral and [intravenous (IV)] pain medication. Within 5 hours she demonstrated tachycardia (HR 140 's) with an increase in temperature to $101^{\circ} \mathrm{F}$ (a further increase may have been masked by the administered analgesics/ antipyretics). Despite IV pain medication, the patients' pain continued to increase. The initial lab tests demonstrated the patient had leukocytosis with a white blood cell count of 20.2 thousand/ $\mu \mathrm{L}$. The red blood cell count (4.73 million cells/ $\mu \mathrm{L}$ ), the hemoglobin $(13.8 \mathrm{~g} / \mathrm{dL})$ and hematocrit $(42.6 \%)$ were all normal. The patient was followed for hemolytic issues. Blood cultures taken upon arrival later demonstrated no apparent growth. An ultrasound verified a non-specific edema within the soft tissue of the
Correspondence: Cindy L. Austin, Trauma \& Burn Research Center, Mercy Hospital, 1235 E Cherokee, Springfield, MO 65804, USA. Tel: +1.417.820.7464.

E-mail: Cindy.austin@mercy.net

Key words: Epinephrine; Necrotizing fasciitis; Clostridial perfringens; Gas gangrene; Allergic reaction.

Contributions: KL and GG proposed case report for study review journal submission. SJT and CLA obtained IRB approval for study. GG, SJT, and CLA supervised the conduct of data collection and managed the data. $\mathrm{KL}$ and GG provided clinical expertise and patient treatment course of details data. SJT and CLA drafted the manuscript. All authors contributed substantially to manuscript revision for ensuring accuracy and take responsibility for the paper as a whole.

Conflict of interest: the authors declare no potential conflict of interest.

Received for publication: 30 August 2016. Revision received: 14 December 2016.

Accepted for publication: 21 March 2017.

This work is licensed under a Creative Commons Attribution 4.0 License (by-nc 4.0).

(C) Copyright K. Larson et al., 2017

Licensee PAGEPress, Italy

Emergency Care Journal 2017; 13:6256

doi:10.4081/ecj.2017.6256

affected area, with no drainable fluid. (Day 1) Patient was administered [non-steroidal anti-inflammatory drugs (NSAIDs)] for inflammation, IV broad spectrum antibiotics to contain infection and analgesics to control for the increasing pain. The patient was preliminarily diagnosed with bacterial myositis and sepsis (Day 1). Once admitted the pediatric physician became concerned due to the rapid progression of the symptoms and consulted a surgeon for evaluation. The surgeon ordered an immediate MRI which demonstrated extensive gas in the quadriceps muscles, (especially in the vastus lateralis and adductor muscles) along with extensive edema and enhancement. These findings were concerning for an infection with a gas-forming organism. The patient went to the operating room (Day 1) for leg incision, drainage, and skin debridement (Figure 1A). Post-operative pathology showed necrotic skeletal muscle with acute inflammation. Clostridium perfringens was identified in the three specimens (Table 1, for a procedure overview).

On day 3, she underwent a second surgery for leg irrigation, further debridement, and placement of Wound VAC. Broad spec- 
trum antibiotics were adjusted in accordance with lab susceptibility testing results. Blood cultures indicated no growth. The patient continued on fluids, targeted antibiotic therapy and [patient-controlled analgesia (PCA)] for pain control. Patient started having muscle spasms in the affected leg; consequently diazepam was added to medications.

On day 15 , the patients' main complaint was pain, PCA support was continued with antibiotic therapy. By day 20, blood and urine cultures obtained were negative. Patient underwent fourth surgical procedure on day 23 for [split thickness skin grafting (STSG)] with leg debridement and wound vac closure (Figure 1B). On day 26, patient moved from Pediatric Intensive Care Unit to the floor and on day 28 Wound VAC takedown with transition dressing changes that include topical antiseptic and antibiotic ointments. Antibiotic therapy included cefepime as an intravenous piggy back, urine was positive for gram negative rods (low level contaminated), blood cultures negative. Patient was discharged home after a LOS of 34 days. The patient continued physical therapy and follow up in the outpatient wound clinic (Figure 1C) for 5 months and successfully returned to physical activities. The patients' final diagnosis was necrotizing fasciitis, gas gangrene caused by Clostridium perfringens, with infective myositis of the left thigh.

According to EAI guidelines, patients are to go to the ED immediately after injection. However, this patient waited 24 hours before being admitted into the ED for suspected compartment syndrome. Initially, an infected EAI was suspected to be the culprit for contamination of Clostridial spores, clarification testing of the EAI was not performed.

\section{Patients and methods}

A review of the literature using the PubMed database for gas gangrene, myonecrosis and adrenaline in which subjects were $\leq 18$ years old, was performed. The references of qualifying articles were examined to identify other articles. Articles with patients older than 18 years old, gas gangrene or myonecrosis attributed to another bacterial species were excluded from this study. The following data was collected: sex, age, site of injection, time postinjection of hospital admittance, signs/ symptoms shown upon admittance, bacterial species, medications given, surgical procedures used and outcome. The study was submitted to the Mercy Institutional Ethics Review Board and received expedited approval.

\section{Results}

In this review of the published literature, we found three pediatric patients $(\leq 18$ years old) with $C$. perfringens infections secondary to epinephrine injections, with only one patient surviving (Table 2). Commonly, all were healthy females with similar presenting symptoms most notably; persistent severe pain, fever, inflammation, elevated heart rate, low blood pressure, and feeling of malaise. Of those reported, the initial predominant symptom was pain at the injection site, starting between 6-12 hours post-injection.

\section{Discussion}

Classically, clostridial myonecrosis

Table 1. Patient treatment timeline.

\section{Day Procedure}

1 Initial surgical debridement

3 Wound irrigation, secondary debridement and wound VAC

8 Further wound irrigation, application of dermal repair scaffold dressing and wound VAC

23 Final debridement, STSG and wound VAC take down

VAC, vacuum assisted closure; STSG, split thickness skin grafting. Patient underwent four surgical procedures within 23 days.
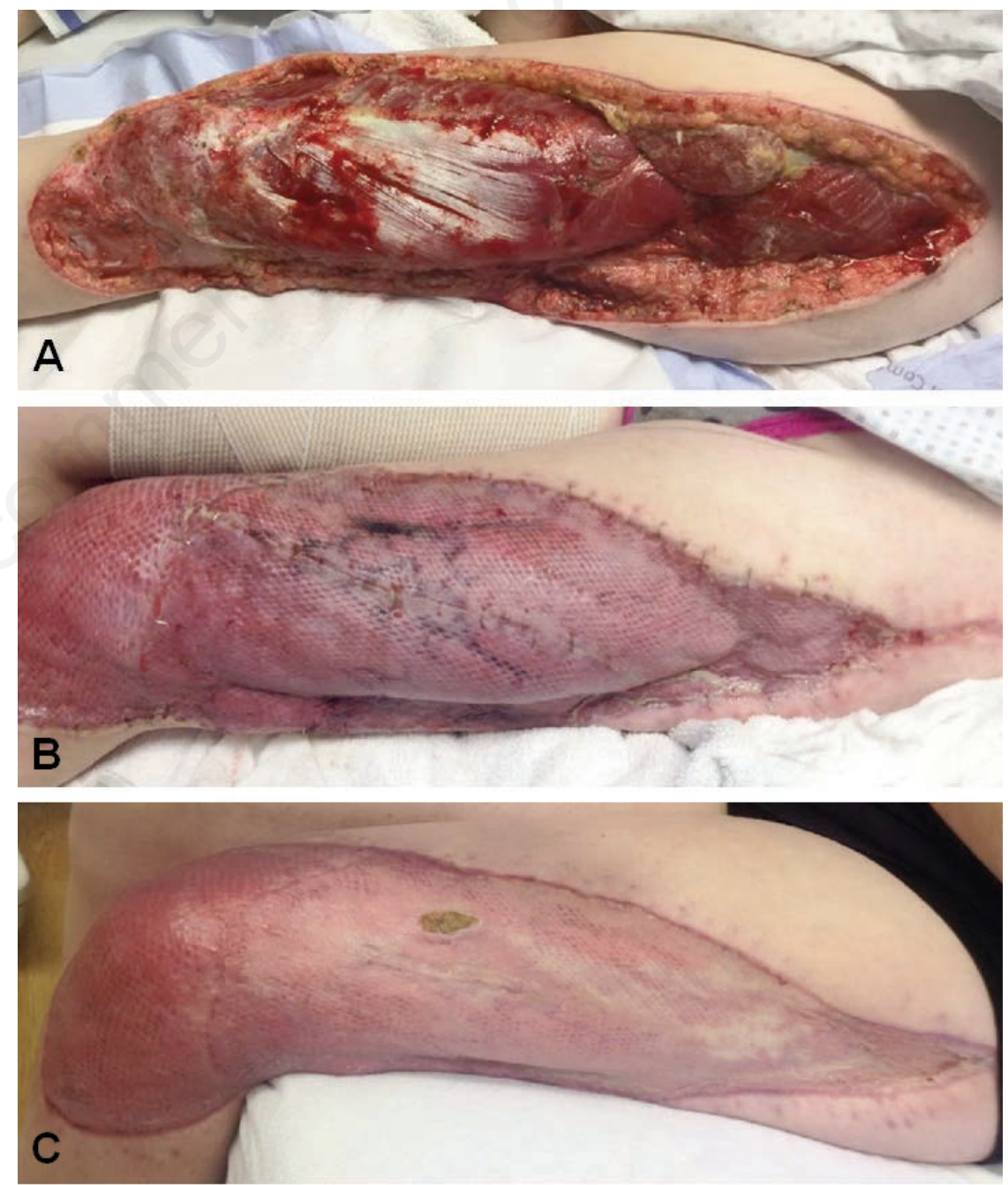

Figure 1. Photographs representing course of treatment: day 1, intra-operative photo of left thigh post surgical debridement (A); day 23, fresh STSG of left thigh (B); day 54, healed left thigh $(\mathbf{C})$. 
Table 2. Pediatric clostridium infections following epinephrine injections.

\begin{tabular}{|c|c|c|c|c|c|c|c|c|c|}
\hline Author & Sex & $\begin{array}{l}\text { Age } \\
\text { (year) }\end{array}$ & $\begin{array}{l}\text { Site of } \\
\text { injection }\end{array}$ & $\begin{array}{l}\text { Time post-injection } \\
\text { symptoms } \\
\text { of hospital } \\
\text { admittance }\end{array}$ & Signs/ & Species & Medications & Surgery & Outcome \\
\hline Present case & 우 & 16 & Thigh & 24 hours & $\begin{array}{l}\text { P, F,HR, G, BP, } \\
\text { I, muscle spasm }\end{array}$ & C. perfringens & $\begin{array}{l}\text { Piperacillin/ } \\
\text { taxobactam, } \\
\text { cefipime }\end{array}$ & Yes & Alive \\
\hline $\begin{array}{l}\text { Gaylis } \\
\text { (1968) }\end{array}$ & 우 & 18 & Thigh & 3 days & $\begin{array}{c}\text { P, F, HR, G, } \\
\text { M, I,C, BP }\end{array}$ & C.welchii ${ }^{*}$ & penicillin & Yes & Expired \\
\hline $\begin{array}{l}\text { Teo et al. } \\
\text { (1981) }\end{array}$ & 우 & 13 & Buttock & 3 days & $\begin{array}{l}\text { P, F, HR, G, M, } \\
\text { I,BP, septicemia }\end{array}$ & C. perfringens & $\begin{array}{l}\text { Hydrocortisone, } \\
\text { penicillin, } \\
\text { metronidazole }\end{array}$ & Yes & Alive \\
\hline $\begin{array}{l}\text { Tonge } \\
\text { (1957) }\end{array}$ & 우 & 15 & Thigh & $\begin{array}{l}24 \text { hours } \\
\text { circu }\end{array}$ & $\begin{array}{l}\text { P, HR, I, M, C, } \\
\text { IBP, peripheral } \\
\text { latory failure, toxe }\end{array}$ & mia ${\text { C. } \text { welchii* }^{*}}^{\mathrm{d}}$ & $\begin{array}{l}\text { Eschatin, } \\
\text { soxy-cortiscosterone } \\
\text { acetate, } \\
\text { radrenaline, penicillin, } \\
\text { antitoxin }\end{array}$ & No & Expired \\
\hline
\end{tabular}

P, pain; I, inflammation/swelling; F, fever; BP, low blood pressure; HR, elevated heart rate; M, malaise/ill; C, crepitus; G, gas-gangrene. ${ }^{*}$ C. perfringens was formerly known as $C$. welchii.

infection is described as having an acute presentation and a fulminant clinical course. ${ }^{7}$ The infection can occur by one of three methods: (A) areas of major trauma, surgery or as a thermal burn complication. (B) Minor trauma specifically punctures of the skin including intravenous administration of drugs, intramuscular injections of epinephrine, and insect bites. (C) Non-traumatic or spontaneous infections, where either there is an activation of dormant clostridial spores in old scar tissue ${ }^{2}$, or by bacteremic spread of the organism from the primary infection site (i.e. gastrointestinal or genitourinary).

Because the infection progresses so quickly, any delay in either clinical diagnosis or treatment can be fatal. ${ }^{7}$ The inception is abrupt, often within 4 to 6 hours of the injury ${ }^{7}$. Sudden, severe pain in the area of infection is an early clinical sign. ${ }^{2}$ During surgical examination, the infected muscle is dark red to black, non-contractile, and does not bleed when cut. ${ }^{2}$ Radiological imaging may show tissue gas outlining fascial planes $^{2}$ and muscle bundles. ${ }^{8}$

In this case, after a review of the related literature, the catalyst for Clostridial spore development appeared to be the simultaneous introduction of epinephrine into the intramuscular environment, creating optimal conditions for rapid anaerobic growth. In studies before 1984, epinephrine was known as adrenaline. Early studies by Cooper $(1946)^{9}$ and Evans et al., (1948) ${ }^{10}$ demonstrate a marked ( 1 x $10^{5}$ fold $)$ decrease in the minimum lethal dose of Clostridium perfringens (previously called Clostridium welchii) when injected together with epinephrine; the enhancement of lethal dose was only observed within the $2-3 \mathrm{hr}$ vasoconstriction window induced by the epinephrine dose. ${ }^{10}$

\section{Preventative measures}

Recommendations to reduce the risk of infections via self injection remains a challenge since Clostridial spores are often found as a component of normal skin flora and are not reduced by alcohol swabbing, which may actually only disperse the spores. ${ }^{11}$ The use of plain soap and water can be used to try to remove the spores from the skin, and thus mitigate the risk of infection. ${ }^{12}$

With the significant increase $(67 \%$ in the past seven years) in the number of patients using epinephrine auto-injectors ${ }^{13}$ we suspect the occurrence of infections presenting to ED may likely increase. Given $C$. perfrigens infections via injections are not commonly seen, ED physicians need to be vigilant in both pediatric and adult patients presenting post epinephrine injection.

\section{Conclusions}

These findings demonstrate that epinephrine injections in pediatric and adult patients increase the risk for Clostridium perfringens infections, subsequently gas gangrene and necrotizing fasciitis. Clinical signs include persistent pain, fever, inflammation, elevated heart rate, and low blood pressure in patients presenting to the emergency department immediately after utilization of an EAI. A delay in diagnosis and treatment can lead to more serious complications like amputation or death.

\section{References}

1. Sparks CSD. Necrotizing fasciitis. In: Yamamoto LG, Inaba AS, Okamoto JK, Patrinos ME, Yamashiroy aVK, eds. Case based pediatrics for medical students and residents. Vol 1. 1 ed. Hawaii: Department of Pediatrics, University of Hawaii John A. Burns; 2003. p. 716.

2. Mader JT, Calhoun J. Bone, joint, and necrotizing soft tissue infections. In: Baron S, ed. Medical microbiology. 4 ed. Galveston, TX: University of Texas Medical Branch at Galveston; 1996.

3. Revis DR. Clostridial gas gangrene. 2014. Available from: http://emedicine.medscape.com/article/214992-overview\#showall

4. Gaylis H. Gas gangrene and intramus cular injection. Br Med J 1968;3:59-60.

5. Tonge JI. Gas gangrene following the injection of adrenaline in oil. Med J Aust 1957;44(:936-938.

6. Teo WS, Balasubramaniam P. Gas gangrene after intramuscular injection of adrenaline. Clin Orthop Relat Res 1983:206-207.

7. Assadian O, Assadian A, Senekowitsch $\mathrm{C}$, et al. Gas gangrene due to Clostridium perfringens in two injecting drug users in Vienna, Austria. Wien Klin Wochenschr 2004;116:264-267.

8. Chew F, Mulcahy H, Ha AS. Musculoskeletal imaging: a teaching file. Philadelphia, PA: Lippincott Williams \& Wilkins; 2012.

9. Cooper EV. Gas-gangrene following injection of adrenaline. Lancet 1946;1:459-461.

10. Evans DG, Miles AA, Niven JS. The 
enhancement of bacterial infections by adrenaline. Br J Exp Pathol 1948;29:2039.

11. Ahmad FJ, Darrell JH. Significance of the isolation of Clostridium welchii from routine blood cultures. J Clin Pathol 1976;29:185-6.
12. Amin N, Pickering AJ, Ram PK, et al. Microbiological evaluation of the efficacy of soapy water to clean hands: a randomized, non-inferiority field trial. Am J Trop Med Hyg 2014;91:415-23.

13. Koons C, Langreth R. How marketing turned the EpiPen into a billion-dollar business - mylan's marketing turned the allergy device into a must-have. 2015. http://www.bloomberg.com/news/articles/2015-09-23/how-marketing-turned-the-epipen-into-a-billion-dollarbusiness 